\title{
IN MEMORIAM PADRE ENRIQUE RIVERA DE VENTOSA (1913-2000)
}

"La lección que me ha dejado la vida es la que intento practicar ahora. Soy un entusiasta del tiempo presente. El pasado, tan enorme a través de la historia, nos debe iluminar el presente. El futuro debe ser algo que nosotros tengamos presente en nuestro presente.

La realidad es que yo tengo que actuar en el tiempo presente. El tiempo presente tenemos que realizarlo con sencillez. Nuestra conciencia nos dicta lo que tenemos que hacer.

En este momento yo estoy en el presente, ¿qué tengo que hacer? Responder a las preguntas que me están haciendo. Después el siguiente presente, ¿cuál es? ¿Echarme a la cama?, pues me echo a la cama. No me hago problema con los proyectos de futuro. Soy un entusiasta del presente. Carpe dien. Aprovéchate del día. Y lo del evangelio: Sufficit diei malitia sua (Le basta al día su malicia).

Yo, ahora, estoy en la actitud de ver cómo pasamos el día de hoy tranquilamente, santamente y a ver si podemos hacer un poco de bien. Es mi consigna. Contra el mal hay que luchar con el bien. Si hay mucho mal, vamos a ver si desde mañana intentamos con nuestro bien, hacer que el mal sea menos. Esa es mi actitud. Nada más. No hago problema del mañana, y esto me ha traído una paz, una tranquilidad y una serenidad extraordinaria. Vivo según lo que me toca hacer en el momento.

Por tanto, soy un entusiasta del presente vivido desde esos orígenes del evangelio, como cristiano, y desde los orígenes del franciscanismo, como franciscano".

Con estas palabras del eminente pensador cristiano, Enrique Rivera de Ventosa, recientemente desaparecido, que tantas veces se asomó a estas páginas para compartir su extraordinaria sabiduría - palabras que él mismo dejó escritas y que fueron leídas en las exequias celebradas el pasado día 24 de febrero en la Capilla de los PP. Franciscanos Capuchinos de Salamanca, en el transcurso del funeral que se celebró con gran solemnidad y emoción-, damos inicio a este modesto y sincero homenaje, con la certeza de que será acogido en religioso silencio y admiración por las muchas personas que tuvieron el privilegio de conocerle, bien personalmente, o bien a través de sus muchos trabajos. En todo caso, tanto éstos como aquellos que se acerquen por vez primera a la imponente figura de este fraile Franciscano Capuchino, es muy posible que encuentren motivos para la reflexión ya que, como se verá, la fuerza del amor a Dios que ha impregnado toda su vida y su obra, ha alcanzado las cimas magistrales de la generosidad y la ofrenda ilimitada hasta el último instante de su paso por este mundo. A su vez, ha dejado una huella indeleble en los que tanto le amábamos. Y ese amor, en el que se entremezcla también la gratitud y una profunda emoción ante su tránsito, es el que en estos días dilata de manera singular el espacio disponible en revistas y medios de comunicación -casi siempre tan escaso-, para hacerse eco de la personalidad vital e intelectual del P. Enrique: "Tratándose de él..., lo que sea", manifiestan los responsables de las publicaciones, y esto ya lo dice todo.

Pues bien, Enrique Rivera Montalvo había nacido el día 31 de octubre de 1913 en la casa-escuela de Ventosa de la Cuesta (Valladolid) donde su padre era maestro. Por eso le gustaba llamarse Rivera de Ventosa e incluso algunos de sus primeros trabajos los firmó con el nombre de Feliciano de Ventosa. Guardaba un hermoso recuerdo de aquellos felices años de su infancia transcurridos en compañía de sus padres y hermanos, y sentía una ternura especial hacia su madre, a la que recordaba con mucha frecuencia en sus conversaciones. En cuanto a su padre, cabe recordar que el título que recibió para ejercer la docencia de maestro, conforme a lo prescrito en esa época para estos casos, se lo concedió el Rector de la Universidad de Salamanca, que era en ese momento D. Miguel de Unamuno, dándose la circunstancia de que fue el primero que concedió siendo Rector. Naturalmente este fue siempre un hecho significativo para el P. Enrique, como es bien sabido extraordinario conocedor del pensador y poeta.

El Prof. Rivera ingresó en 1923 en el Seminario de los PP. Capuchinos de El Pardo (Madrid), cursando estudios de Filosofía en Montehano (Santander), Teología en León y en la Universidad Gregoriana de Roma, donde se graduó en Filosofía en 1942. Durante el curso 1943-44 inició su carrera docente impartiendo clases de Filosofía en esta ciudad. En 1943 se doctoró en Filosofía por la Universidad Gregoriana de Roma, con pre- 
mio extraordinario, con el tema: "El voluntarismo de San Buenaventura", que tanta trascendencia tendría después en su pensamiento; y también durante aquellos años (1941-1942) conseguía en la Biblioteca Vaticana el diploma de Biblioteconomía. Fue en 1953 cuando recibió la invitación de la Universidad Pontificia de Salamanca para dar un cursillo, actividad que prosiguió realizando años después, convirtiéndose en profesor de la misma. En 1954 fundó la revista Naturaleza y Gracia y en 1958 se produjo el inicio de su línea de investigación en torno a la Filosofía de la Historia. Tras varios meses de estancia en Múnich, ciudad en la que hizo grandes amigos, regresó a Salamanca donde fue nombrado Profesor de Filosofía de la Historia en la Universidad Pontificia. Y en años sucesivos pasaría de ser nombrado profesor extraordinario de Historia de la Filosofía, a profesor adjunto del Centro Ecuménico de Salamanca, catedrático de Historia de la Filosofía y finalmente catedrático emérito, que era la condición que ostentaba en el instante en el que se produjo su tránsito el pasado día 23 de febrero, a la edad de 86 años, en el madrileño Santuario de S. Antonio, sito en la C/ de Bravo Murillo.

Paralelamente a su docencia entre 1966 y 1969 dictó cursos en el Centro Ecuménico de Salamanca y visitó como conferenciante o investigador, en varias ocasiones, diversos centros extranjeros sobre todo franceses y alemanes.

Su ingente obra abarca más de un centenar de pequeñas monografías y rebasa el millar de recensiones. De ellas se hizo eco Antrhopos, 122/123 (1981) dentro del monográfico: "E. Rivera de Ventosa: Pensador cristiano actual" y pueden encontrarse, más actualizadas, en la obra de Gonzalo Díaz: Hombres y documentos de la Filosofía Española, VI (1998), 796-805. Sin embargo, y dado que una de las características del P. Enrique ha sido su trabajo infatigable, a la larga lista de artículos que aparecen en la mencionada obra, habría que añadir muchas más. Así hay que destacar, entre otras, su extraordinaria contribución: Die Philosophie des 17. Jahrhunderts que mereció su presentación en el Aula Magna de la Universidad Pontificia de Salamanca en un acto conjunto organizado por las Facultades de Filosofía de la Universidad Pontificia de Salamanca y de la Universidad de Salamanca que se celebró el día 3 de diciembre de 1988. Este trabajo preparado para el volumen de la Historia de la Filosofía de F. Ueberweg sobre el pensamiento de la Península Ibérica en el siglo XVII, dirigido por $\mathrm{H}$. Méchoulan, le produjo una inmensa satisfacción.

Son muchos los trabajos que se han ido realizando en torno a la importante obra del Prof. Rivera cuyo pensamiento ha estado enraizado en la línea franciscana, pero "inserto en el personalismo comunitario". Se sintió siempre especialmente motivado por la metafísica y la filosofía de la historia. La línea de su investigación le permitió subrayar su afinidad con las tesis de autores como S. Buenaventura, S. Agustín, Escoto, Sto. Tomás, S. Juan de la Cruz, Blondel, Laín Entralgo..., que aparecen reflejadas en la totalidad de su obra, con desigual significación, junto a Miguel de Unamuno, Ortega, Zubiri, Hegel y una galería interminable de autores de distinta posición.

Aprendiz infatigable, siempre alumno por su afán de saber y documentarse, hombre de talante abierto, dialogante, con la apertura que da la crítica constructiva —única clase de crítica que aceptaba_, ${ }^{1}$ muchas veces le confié mi impresión de que encontrarme ante un pensador del s. XXI, algo que aceptaba de buen grado. Pues bien, esa capacidad de buscar la verdad, de adentrarse en el hontanar del que fluye la fuente de la vida mística, mantuvo su espíritu alerta, expectante ante alguna clase de luz para sus muchas preguntas. Se trata de esa intuición que embarga la mente y el corazón de un pensador nato, como era él, en función de la cual se mantiene el convencimiento de que existe en algún lugar una respuesta, una salida a la interpelación, un paso más respecto de lo que ya se ha encontrado. Sin duda ninguna esa luz la encontró hace unos años en el pensador español Fernando Rielo, de quien se manifestaba ferviente admirador y a quien consideraba "su alma gemela". Son muchísimos los testimonios que de ello ha ofrecido a sus allegados, profesores, amigos, compañeros... Incluso hace notar esta "simpatía" hacia el pensamiento rieliano en la mencionada obra de G. Díaz (p. 798). Y no fue sólo la obra de Rielo, con una metafísica propia, verdaderamente singular, ni su obra

1 "Se nos enseñó la crítica individual - examen de conciencia - pero no la colectiva. Y, para mí, es patente, con la historia bien abierta, que no hay posibilidad de progreso sin autocrítica: tanto en el plano individual como en el colectivo". En Muñiz Rodríguez, Vicente: "Sobre el pensamiento cristiano del Dr. Enrique Rivera", Anthropos 122/123 (1981) 69. 
poética simplemente la que ha marcado los últimos años de la trayectoria personal e intelectual del P. Enrique, ha sido también la espiritualidad del Prof. Rielo y su propia experiencia vital la que impregnó la existencia del P. Enrique en un optimismo, si cabe mayor que el que siempre tuvo, ante episodios de onda trascendencia para el ser humano como son precisamente el tránsito de esta vida a otra celeste. Esa experiencia del gozo ante un Padre, el sentimiento de conciencia filial expresado por Rielo y tan hondamente sentido por el P. Enrique, según sus propias palabras, ${ }^{2}$ había constituido un revulsivo único para su quehacer intelectual y su vida espiritual. Comentando hace unos meses los fragmentos de un poema rieliano afirmaba:

..."No he conocido en ningún autor, en ninguna correspondencia, algo que se parezca a esto: "Te saqué de toda nada/ con sólo beso en tu espíritu"/ "¿Por qué te quejas de mí?". La respuesta del alma es: "Me has amado: ¡ya lo sé!". "¿Te libré de la malicia/ conservándote inocente de la sierpe venenosa?". " Este hecho, todo lo bueno, la inocencia que ha tenido, todo depende de Él: "Me has amado: ¡ya lo sé!". "¿Has hecho de montes valles/ con mis manos en tus manos?". En un lenguaje bíblico, porque esto es lo del precursor cuando decía: "vengo a allanar valles y a suprimir collados" es lo que aquí dice: "¿Has hecho de montes valles/ con mis manos en tus manos? / "Me has amado: iya lo sé!". ¿Y los ángeles celebran...". Esto es una cosa que solamente se encuentra en Rielo, es decir, lo que llamo yo la canonización de la vida mística, en cuanto que mística es esa cognitio affectiva experimentalis...".

No es este el momento para expresarlas, pero guardo celosamente en mi corazón y en mi mente numerosas confidencias realizadas en el recoleto despacho de la casa conventual de los PP. Capuchinos de Salamanca, donde tantas veces nos reunimos -en sesiones de trabajo, así las llamaba él — para compartir un mismo y religioso ideal. Algún día no muy lejano determinados pensamientos de significativa hondura y rigor espiritual quizá puedan brotar entre las líneas de nuevos textos dedicados a su persona. Entre tanto, queda el testimonio de los importantes trabajos de investigación publicados por el P. Enrique en torno a la obra de Rielo, y otros presentados en diversos Congresos. Hay que resaltar aquí su labor infatigable, su capacidad titánica de trabajo - uno de los rasgos propios de su carácter que ha durado hasta el final de sus días--, que le ha llevado a dejar numerosas fichas de trabajo y grabaciones jrealizadas en medio de su grave enfermedad! con el objeto de que vean la luz nuevos trabajos, que otros tendremos que llevar a buen término, como muestra de su inmenso amor y admiración hacia la vida y la obra de Fernando Rielo. Baste decir que el 8 de diciembre de 1999, festividad de la Inmaculada Concepción, aparece la siguiente anotación en su diario —en una sencilla hoja que él mismo tituló con el nombre de "Mi Vida"-: "dos dualidades en mi vida: 1) San Francisco y 2) Rielo", haciendo constar en su "orden del día': "mañana: atender a las publicaciones-asuntos...; tarde: lo de Rielo; noche: S. Francisco".

Una vez más, ante la tarea amable, pero no exenta de responsabilidad, de tratar de glosar la personalidad extraordinaria del P. Enrique Rivera, se muestra descarnada la limitación de la palabra, que se revela incapaz de trasladar lo que guarda el corazón y la memoria; se desborda el ánimo y se pierde en miles de matices ante la grandeza de su espíritu. Ello constituye una muestra de que la sabiduría humana, que la poseía con creces el Prof. Rivera, y que ha despertado siempre una profunda admiración y respeto en todos los que lo hemos

2 El tema de la conciencia filial to ha venido tratando siempre, y especialmente en los diferentes trabajos publicados en los últimos años en torno a las vivencias primarias del alma de $S$. Francisco, que era una de sus obras más queridas. Es más, antes de su fallecimiento ha dejado grabado el último capítulo que le quedaba para finalizar el libro sobre las vivencias trinitarias de San Francisco. Hay que decir además, que una de las obras que me cabe el honor de llevar a buen término, por expreso deseo suyo, y para las cuales ha dejado preparado un material ingente, tiene que ver con las convergencias que él había detectado entre Fernando Rielo y San Francisco de Asís, relacionadas precisamente, entre otros matices, con la conciencia filial.

3 Cf. Rielo Pardal, F., En las vírgenes sombras, Ed. Fundación Fernando Rielo, Sevilla, (1994) 99. Hay que decir que aunque el P. Enrique estaba fascinado por toda la obra de Rielo, este libro en concreto era algo preciadísimo y en verdad singular para éi.

4 Rivera, E. Comentarios en torno a la obra de F. Rielo. Grabaciones inéditas realizadas antes de su fallecimiento en el Santuario de S. Antonio, PP. Capuchinos de Madrid. 
conocido, empequeñece ante la reciedumbre de su persona, exhibe sus límites y se posterga ante el testimonio de la vivencia del amor a Dios. Y, a la vez, engrandece su ya magna obra. Porque si del P. Enrique se destaca su erudición y sus vastos conocimientos, que han sido siempre reconocidos, existiendo una unanimidad en lo que concierne a la riqueza de la misma y al sinfín de sugerencias para la investigación que ha dejado abiertas, no todos pueden decir que lo conocieron en profundidad. Por eso considero un privilegio y un hecho providencial haberme encontrado con él hace unos años, entablándose entre ambos una singular corriente de afecto, que por mi parte me ha llevado a considerarle padre, hermano, amigo, mentor, maestro... por la tutela que ha ejercido conmigo hasta que se ha producido su tránsito. Es, sobre todo, un don haber podido seguir tan de cerca su trayectoria vital e intelectual, que me ha permitido acercarme así no sólo al eminente pensador que ha sido, sino, sobre todo, a la persona.

Y es en esa recámara, en los perfiles de ese santuario propio de cada ser humano, que de vez en cuando tenemos la gracia de entrever algunos, donde se perfila la talla de un hombre, de un hijo de Dios. Y el P. Enrique era muy parco en hablar de sí mismo. Apenas si lo hizo en el transcurso de su enfermedad para dar cuenta de ella. Sobrio en ese conocimiento del proceso de su salud, que dejaba en manos de sus médicos y superiores, se prodigaba en las excelencias ajenas, en el entusiasmo hacia los éxitos de sus numerosos amigos, algunos de ellos antiguos alumnos, que le acogían como verdadero maestro, por más que este fuera un título que trasladaba de inmediato a Cristo, "el único Maestro", cuando se lo dábamos a él. Pero el P. Enrique no necesitaba decir nada. Bastaba la elocuencia de sus gestos: amabilidad, nobleza, humildad, generosidad... La magnanimidad de su corazón bondadoso, que mostraba la fidelidad en la vivencia del espíritu franciscano, inundaba de paz y de gozo a todos los que nos acercábamos a él. Siempre cercano a las necesidades y atentísimo incluso hasta en las efemérides. Exquisito en el trato, con una fe rotunda, sin fisuras, no tenía concesiones hacia lo que fuera menos bueno y santo en sí mismo, a la vez que se mostraba extraordinariamente compasivo hacia las debilidades ajenas, que cubría con una caridad ejemplar.

Resultaba sorprendente que un hombre de su talla y rigor, con esa voz tan singular, ágil, dinámica, rebosante de entusiasmo, pudiese descender tan fácilmente a la escucha de aquello que se le trasladaba y no considerase pérdida de tiempo atender una visita o dedicar un espacio de su preciado tiempo para leer los trabajos que le hacíamos llegar. Todo lo contrario. Era un interlocutor perfecto, porque no se limitaba a oír, sino que guardaba en su interior lo que se le decía y lo que se desprendía de los textos que se le entregaban, haciéndolos objeto de su propia reflexión de modo que, con una brevedad asombrosa, se escuchaba su voz al otro lado del hilo telefónico desgranando sugerencias, impresiones, expectativas..., todo lo que consideraba podía ser útil para el otro. ¡Si muchos profesores aprendieran de este talante, cuántas personas saldrían adelante, cuántos valores en ciernes no se perderían! Jamás en sus labios la prepotencia ni la vanagloria de sus muchísimos conocimientos. Nunca la distinción de personas, la elección de los "bien preparados" para departir con ellos, sino la acogida inteligente e intuitiva, el talante del verdadero maestro que sabe extraer de todos los que le rodean los valores que implícitamente los adornan.

Honesto y coherente, en las pocas entrevistas que se le han hecho — se destaca la mantenida con el Dr. Muñiz Rodríguez, Superior de la Fraternidad de Salamanca y antiguo alumno suyo, a quien profesaba singular afecto y ternura, como acontecía con todos los miembros de su comunidad-,, 5 hacía notar su posición vigorosa y bien meditada en muchos de los aspectos de la vida y la época que le había tocado vivir: preocupaciones por el pensamiento cristiano, cuestiones políticas, sociales, eclesiales, comunitarias... Y es también una de

5 Cf. Muñiz Rodríguez, Vicente: Sobre el pensamiento cristiano del Dr. Enrique Rivera " Anthropos, o.c. 68-71. Una muestra de la exquisitez del P. Enrique es la confidencia que hace pocos días me transmitió el autor de esta entrevista. Al parecer, ante la oferta de practicarle una serie de preguntas para ser publicadas en Anthropos el natural pudor del P. Enrique ante lo que pudiera decirse de él brotó de inmediato, ante lo cual el P. Vicente le ofreció la posibilidad de que fuera el mismo P. Enrique quien las preparase, sugerencia que aceptó encantado y agradecido. No obstante, ante el interés que ofrecía la presencia de una personalidad poco común como era la del P. Enrique, al final de la entrevista el P. Vicente formuló una nueva pregunta que no había sido prevista, ante la cual, como podrá apreciar el lector, se percibe claramente en la respuesta que el P. Enrique no deseó entrar en consideraciones personales: "Y, como no quiero quebrantar normas de mi vida, como la de hablar de mí mismo cuanto menos, mejor, creo que podemos concluir aquí la pregunta". ibíd. p. 71. 
las escasas ocasiones — cuando no única — en las que podemos detectar su personalidad basándonos en sus propias palabras:

"...Respecto a mi nombre, crédito y fama, he tenido, por convicción y vocación, poco interés. Hasta, con frecuencia, llegar al descuido. Me ha repugnado, ya desde mi juventud, 'aparecer'. Prefiero sencillamente 'ser'. Lo demás vendrá o no vendrá. Pero con 'ser' me basta; y mi conciencia me dice que he cumplido mi obra. Y esto es lo que importa. Más que el necio 'aparecer' que, por otro lado, he visto cómo truncaba tareas investigadoras en pro de un aplauso o una adulación efímera". ${ }^{6}$

Esta era su postura: realista, directa, clara, positiva, evangélica. Lo demás no tenía sentido para él. Constituía sencillamente un absurdo. Y eso lo sabíamos muy bien quienes lo conocíamos, pero no dejaba de causar asombro por lo inusual en determinados estamentos universitarios, donde mentes de menor brillantez y menos lúcidas se empeñan en seguir otros derroteros, esos que justamente desdeñaba el Prof. Rivera. Así, con esta actitud, ¿a quién podría extrañarle que brotasen a su alrededor, como de ese árbol frondoso mencionado por el Evangelio (Mt 13,32), tantos y tantos amigos? Alain Guy, Noboru Kinoshita, Carlos Sumita, Raul Fornet-Bethancourt, Eudaldo Forment, Cirilo Flórez, Antonio Heredia, José María López-Sevillano... se contaban entre aquellos grandes colegas que él mencionaba con frecuencia en sus conversaciones, de la misma forma que se explayaba en la mención de los trabajos de sus hermanos de comunidad, algunos tan bien preparados, como Vicente Muñiz, Bernardino de Armellada, Dionisio Castillo, Fermín de Mieza...

Su trabajo había despertado un profundo interés en la comunidad japonesa, cada vez más extensa en esta ciudad salmantina. Por eso había sido invitado expresamente poco antes de caer enfermo a la inauguración de la Casa de Japón, sita en la hermosa plaza de San Boal, junto a destacadas personalidades. Y ese también fue un acontecimiento que le llenaba de gozo porque la invitación había surgido de la colaboración en el trabajo intelectual que llevaba a cabo con antiguos alumnos muy distinguidos, como el mencionado Kinoshita, profesor de Filosofía en una universidad japonesa o Shinjiro Ando. Y es que el P. Enrique valoraba, sobre todo, el estímulo que le proporcionaban todos los que se acercaban a él con el noble afán de profundizar en el estudio:

...'Por fortuna, a mí me ha tocado también enseñar a "verdaderos discípulos", deseosos no sólo de asu-
mir mis lecciones sino igualmente de colaborar en mi trabajo intelectual. Con varios de ellos continúo
todavía mi labor investigadora. El estímulo y la alegría que me han proporcionado nunca se lo podré
pagar. Ellos saben bien quiénes son y no hay que citar nombres. En ellos cifro mi mayor y mejor espe-
ranza de poder hacer todavía algo más por el "pensamiento cristiano".

Pero ¡he aquí la clave! el P. Enrique tenía un concepto de persona que es la que se desprende del Evangelio. $\mathrm{Y}$ un aspecto que siempre ponía de relieve y del que él mismo era ejemplo se refiere al amor a la persona, "que es —afirmaba - lo que verdaderamente importa". Y ello lo extraía también de su amado S. Francisco:

"Francisco vive un hondo y profundo respeto hacia el hombre como persona. Al llegar aquí en mi reflexión siento una fuerte tentación de silencio, pues todos mis oyentes han simultaneado mil veces su propia vivencia de respeto al hombre con la del Seráfico Padre".

Para comprender en su verdadero significado lo que con aquellas palabras quería decir, baste recordar un hecho acaecido en el Hospital de la Santísima Trinidad de Salamanca, donde fue intervenido quirúrgicamente sin éxito, al recibir el ejemplar del último libro de su antiguo alumno: el Dr. Fornet-Bethancourt, una de las preclaras mentes que existen hoy en Cuba, y tras la lectura de la dedicatoria, esgrimiendo el libro expresó: "Aquí está la persona". Es decir: está el afecto, anida la gratitud, el recuerdo, la memoria de todo lo que se ha compartido... Está también el reconocimiento, la continuidad en la investigación... y tantas y tantas cosas que no requieren

ibíd. 70 .

8 Rivera, E., "Visión del hombre en San Francisco y la antropología actual". Est. francisc. 78 (1977) 77-78. 
siquiera ser clarificadas. Esos son los gestos que él ponía al servicio de los demás. Por eso tenía la sensibilidad de quien sabe valorar en su justa medida las acciones de otros: él las conocía por experiencia, por haberlas vivido.

Sabía compartir lo que poseía con mucha facilidad. Y eso, una vez más, cuando hablamos de un investigador-creador no es un asunto banal, porque todos sabemos que existe una tendencia a resguardar, a no comunicar, a tratar de soslayar las conversaciones que se refieren a determinados trabajos que son un proyecto o que están en fase de elaboración. El P. Enrique estaba al margen de estas triquiñuelas y actitudes de algunas personas. No tenía - eso lo hemos constatado en sus propias palabras - la pretensión de figurar, ni de constituirse en primicia de nada, aunque lo fuera, a su pesar. Cuántos más pudieran trabajar en esa labor comunitaria mejor. Porque él sabía de la bondad de los frutos surgidos en toda tarea que se verifica con el concurso de otros; de la riqueza que constituye la diversidad de opiniones y los matices que pueden ofrecerse sobre un mismo tema; porque esa es una de las puertas de la creatividad. De ahí que valorase tanto las ideas que le presentábamos, porque ello le obligaba a la precisión y. a la profundidad intelectual; a perseguir una nueva salida, sin duda más fecunda que la que surge en ausencia de la crítica, y de los pros y contras que abren nuevos frentes. Y por eso, lo cual constituye un paso más en la excelencia que aquí constatamos de esta singular persona, entregaba fácilmente los manuscritos de los varios proyectos que simultaneaba siempre - porque no se ocupaba sólo de uno, sino de varios a la vez-, con el deseo y la petición de que le hiciésemos llegar nuestras sugerencias. Esto, dicho así, no tendría mayor importancia. Sin embargo, si a ello le añadimos que lo hacía con la total confianza en la valía de la persona a la que se lo entregaba, elevándola, lo cual, como se diría hoy, proviniendo de él, servía para que creciese la autoestima, no cabe duda de que nos hallamos ante un nuevo gesto que no acostumbra a prodigarse al menos de esta forma.

Y si ya hemos desplegado, en una minúscula parte, algunos de los rasgos de la personalidad del $\mathrm{P}$. Enrique, cuando nos centramos en la espiritualidad que rezumaba, cuya inmediata consecuencia es lo que se ha venido exponiendo, uno de los signos que se destacan es su inocencia evangélica, en absoluto pueril, que rubricaba todos y cada uno de sus actos. Al P. Vicente Muñiz, en la memorable entrevista de la que nos venimos haciendo eco, le dijo que no quería quebrantar normas de su vida, como la de hablar de él mismo, pero si en nuestra labor escudriñadora descubrimos en los hermosos textos en los que hace notar su inmenso amor a S. Francisco de Asís, en un comentario que hace al abrasado amor que el Poverello de Asís tenía hacia nuestra Madre María estas palabras: "El comentario largo a estas líneas quedan para esos momentos de "soledad sonora" que todo franciscano siente repetidamente en su vida", ${ }^{9}$ no podemos por menos de percibir la extraordinaria sensibilidad y la ternura del gran hombre que se esconde tras este pensamiento, a la sazón también ferviente devoto de María.

La reflexión continuada sobre temas tan recurrentes en su obra como: la búsqueda del sentido de la historia, la filosofía griega, el pensamiento bíblico y el franciscanismo, con los matices extraídos de ellos, entre otros, acerca del amor y la vida mística, con la entrega y la forma con la que él lo hizo, nos sugiere la presencia no sólo en su talante intelectual, sino también en su propio quehacer cotidiano, de una manera de ser en la que se percibe una estrecha simbiosis entre lo que va descubriendo su mente y la práctica de su vida. Lo que quiero decir es que, cuando se le ha conocido, como es el caso, los textos de sus obras ponen de manifiesto la coherencia entre sus palabras y su acción. Al fin y al cabo, cuando se trata de temas de espiritualidad es fácil que se deslicen entre las líneas de las reflexión los propios sentimientos del autor. Por eso me parece de gran elocuencia el prólogo que el Prof. Rivera escribió para su libro, San Francisco en la mentalidad de hoy porque permite clarificar esta modesta idea que él refiere a San Francisco, pero que bien podría decirse de lo que depararía de bueno rastrear en sus propios textos, ya que nos "permitirían percibir detalles que muchas veces han sido soslayados" en su personalidad y talante cristiano. Porque el P. Enrique ha dejado no sólo la estela de su vida jalonada por múltiples destellos del amor divino con los que han ido salpicando la memoria y la conciencia de todos los que le hemos conocido. La profundidad vertida en sus textos, el hondo lirismo que rezuman, la contemplación de la verdad y el afán de extraer de ellos, con el rigor de un científico, todo lo que servía para situar en el lugar que le corresponde a lo divino, rastreando en los textos de los pensadores más. genuinos, pone de relieve la calidad de su vida interior.

9 Rivera, E. "La devoción de María en la espiritualidad de S. Francisco", Est. Francisc. 62 (1961) 273. 
Amaba la poesía y la docencia. En realidad era un esteta. Y todo quedaba perfectamente filtrado por su extraordinario humanismo y el sentido de su caridad. Era también un apóstol que desplegaba a través de su tarea pastoral y en calidad de confesor los más sabios y profundos consejos que animan a modificar la conducta humana. En particular le fascinaba el mundo juvenil. Por eso adoptó con tanto entusiasmo mi primer libro, El Evangelio habla a los jóvenes - título sugerido por él一 que corrigió y siguió con auténtica ilusión y hasta aceptó prologarlo. En este sentido, hay que decir que admiraba la línea de trabajo de G. Salvatori, estudioso del santo de Asís, por cuanto le había mostrado "la praxis de esa pedagogía eterna que no impone docencias, sino que hace brotar la verdad de la misma inteligencia del alumno", para añadir a continuación:

\footnotetext{
"G. Salvadori, de quien dice María Sticco que amó, contempló e imitó hasta la muerte a San Francisco, será siempre un perenne modelo de acción franciscana frente a todo pesimismo enervante. Especialmente lo será en el campo del apostolado juvenil. Los jóvenes están siempre esperando quien les enseñe a vivir, siguiendo a los gigantes del espíritu. San Francisco es uno de los que puede estar siempre a su lado. Basta que hallen en su camino al G. Salvadori que sepa llevarles al encuentro del gran Santo". 10
}

Y si además sabemos, porque lo hemos conocido, que el P. Enrique era un hombre de oración, se comprende de dónde sacaba la fortaleza y el coraje para llegar a vivir con la altura y el ejemplo con el que ha sellado no sólo su vida, sino el proceso de la grave enfermedad que le llevó a la muerte, lo cual constituye un capítulo aparte. En efecto, en otro lugar he puesto de manifiesto que es en la enfermedad, en el dolor, y en los procesos de gravedad que, a veces, desembocan en la muerte, donde se conoce bien a las personas. Y esto es debido a lo que he dado en llamar: "singularidad del sufrimiento", donde la conciencia del mismo nos insta a ejercitar la humildad de manera permanente. Es en estos instantes en los que la fortaleza puede convertirse en una estimulante bandera propiciada por la fe o puede surgir el desánimo y hasta escasa energía en una personalidad que quizá hasta ese momento podría haberse revelado como recia y enérgica. En definitiva, este proceso nos revela descarnadamente el interior de una persona. ${ }^{11}$ Pues bien, cuando el P. Enrique fue informado de la gravedad de su enfermedad y de que le quedaban escasos meses de vida, entonó un Salmo de júbilo porque en breve podría ver al Señor. Una vez más, la coherencia y la fe titánica de esta gran persona se abría paso como lo hace el agua que mana sin cesar, potente y generosa, de una cascada cristalina.

El espíritu franciscano le lleva a unirse a ese "canto cristiano del amor que es sufrir y padecer". La perfecta alegría en el dolor, la enfermedad y la conciencia de la debilidad e indigencia humana ante ella. Sin duda, el último período de su vida ha constituido el culmen de su testimonio: obediencia proverbial a todas las indicaciones de sus Superiores - máxima de su vida-, incluso ya enfermo; la disponibilidad a todo lo que se le encomendaba. El optimismo y talante evangélico con el que revestía el Carpe diem horaciano llevado hasta las últimas consecuencias debería bastar para despertar las conciencias. ${ }^{12}$ ¡Qué ejemplo para todos los que

10 Rivera, E. San Francisco en la mentalidad de hoy, Marova, Madrid (1982) 65.

11 Se trata del libro Pedagogía del dolor, Palabra, Madrid, 1999, que, como todos mis trabajos, fue seguido rigurosamente de cerca desde el principio por el P. Enrique. Él mismo me dijo personalmente y también por escrito que le estaba ayudando enormemente en estos momentos tan graves de su vida que preludiaban su tránsito: "Te felicito de nuevo por tu obra, Pedagogía del dolor: En algún pasaje he pensado que reflexionabas en mi vida íntima. Es mi mejor elogio". (Carta personal 27-XI-99). Precisamente, el Superior del convento-enfermería me comentaba no hace mucho que en los últimos meses de su vida junto a la obra de F. Rielo —en la que trabajaba - y tenía como libros de cabecera, había añadido este sobre el dolor.

12 Las numerosas anotaciones en fichas manuscritas y en diferentes cuadernos, que ha realizado en los meses de estancia en el madrileño Santuario de S. Antonio, revelan la meticulosidad y el rigor de su trabajo en la que se incluyen menciones a muchas personas que allí ha recibido, correspondencia, proyectos de investigación, lecturas que llevaba a cabo... Se trata, en suma, del diario de una persona extremadamente activa, que jamás hubiera hecho sospechar a nadie que estaba siendo llevada a cabo por un hombre que se acercaba inexorablemente al fin de sus días. Y creo que esta forma de morir constituye un altísimo y definitivo testimonio del grado de su amor a Dios, su fe titánica y fortaleza vividas hasta el último instante de su existencia. 
sufren! Nada de hablar de la enfermedad ni de la muerte. La salud del espíritu se nutre del trabajo que brota de la oración hecha ofrenda en todo instante. $Y$ así ha permanecido todos estos meses: salpicando sus conversaciones, como siempre, con los preciados textos de las Sagradas Escrituras, sus reflexiones de tantísimos años de dedicación y estudio sobre el pensamiento cristiano, tan querido por él, con la energía de un trabajador nato, que a todos ha sorprendido, manteniendo una disciplina en el convento-enfermería de Madrid que parecía impugnar lo que era ya evidente: su lento, pero inexorable deterioro físico, que no psíquico. Entrevistas, visitas, estudios... y su corazón pletórico ante el amor que percibía en su interior hacia Dios. Escribe en su diario el 29 de agosto de 1999, tras una jornada de trabajo, en la que nuevamente había realizado unas grabaciones para un proyecto común: "¡Qué gran día para mí! Gracias mi Padre del cielo, que me permites hablar tan largo de Ti, mi todo".

Dice el Evangelio que: "de la abundancia del corazón habla la boca" (Mt 12, 34). Me confesaba en mi última visita el pasado mes de diciembre que: ¡se encontraba como nunca! Tenía ocupada la mente con antiguos y nuevos proyectos, pero todos eran concebidos para la mayor gloria de Dios. Nadie podría decir que ha abandonado su presencia sin sentir una especie de alas en el corazón: el vuelo al que era raptado por el amor entrañable, compasivo, fraterno y sincero de este singular Fraile Franciscano. ¿No es esto mística?, ¿no se trata de una honda vivencia espiritual? De mis largas conversaciones ha quedado un reguero de propósitos acerca de lo santo y de lo bueno que todos los seres humanos, con la gracia de Dios, podemos llevar a cabo.

Recibí su última llamada telefónica el pasado $1^{\circ}$ de febrero. Y durante cuarenta minutos, siendo que ya le quedaban pocos días de vida, como lo hace un padre, continuó preocupándose por mi formación intelectual, proporcionándome ideas para los proyectos que teníamos en común, extendiéndose acerca de su inmenso amor al Padre Celestial... Fue la primera vez que habló acerca de su estado físico, pero así, pasándolo por alto, de puntillas, veloz: "he pasado un mal mes de enero...". Eso fue todo lo que pude saber por él acerca de su gravísima dolencia, ya que enérgico, vital, con la misma fuerza de siempre, se adentró en sus recuerdos espirituales, en la exposición de los trabajos que estaba llevando a cabo y las líneas de otros nuevos, haciendo notar que tanto él como yo "teníamos que estudiar mucho"... Me despedí de él muchas veces pero siempre tenía algo más que añadir acerca de lo santo y de lo noble...y la expresión de sus sentimientos proseguía... Son palabras inolvidables que brotaban de la ternura y el talante de un hombre bueno; surcos que se abren en el corazón para no ser jamás abonados por otra tierra que la propia del amor de Dios, percibido a través de los labios del P. Enrique. Constituyen una muestra de lo que puede ser la perfecta convivencia entre los seres que se aman en un mismo Padre en ese hogar celeste del que ya disfruta, y que otros esperamos alcanzar al final de este peregrinaje, que en su caso ha constituido una auténtica gloria para Dios, la Iglesia, la Orden Franciscana Capuchina, el campo del pensamiento y todos a los que ha llegado a través de su magnífica pluma y de su extraordinario e inolvidable espíritu.

Por su interés reproducimos aquí los sentimientos manifestados, en nombre de toda la comunidad, por uno de sus hermanos franciscanos capuchinos a un diario salmantino, tras la desaparición del P. Enrique:

\footnotetext{
"Sentimos la ausencia de un hermano, echamos en falta su vida. Hemos perdido una referencia de cómo vivir hoy franciscanamente. Han sido muchos años de Fraternidad: momentos de convivencia, de oración en común, de reflexiones compartidas, de ejemplos recibidos, de lecciones aprendidas. Un hombre bueno. Humanista generoso con lo humano. Creyente convencido de la bondad que existe en todo corazón humano. Su presencia bondadosa nos hacían sentir paz y bien. Un cristiano confiado de profunda fe. Siempre agradeció de sus padres este don. Una fe purificada y acrisolada en el Evangelio. Una fe que alentaba su esperanza y le hacía, incluso amenazado de muerte por su enfermedad, irradiar optimismo e ilusión. $Y$ un franciscano convencido. A pesar de su mucho saber intelectual, nunca percibimos engreimiento o vanagloria. Con la misma pasión que hablaba a sus colegas en la Universidad, hablaba a las hermanas Úrsulas en sus retiros, o a los feligreses de nuestra iglesia en la homilía. La agonía unamuniana la hizo franciscana. Luchar en la vida, sí, pero con pasión, con humildad y sencillez capuchina, viviendo cada instante con alegría y buen humor, con servicialidad y disponibilidad como todos los sabios y maestros que en esta vida lo han sido". ${ }^{3}$
} 
En efecto, ha sido su vida un ejemplo de sencillez y de conciencia de la valía del tiempo que poseemos. Un testimonio de fidelidad ejemplar que nos insta a vivir el momento presente en la forma como sugieren sus palabras, las mismas con las que hemos iniciado estas líneas. Vivir el entusiasmo ante el instante que nos ofrece la divina providencia para poder aprovechar hasta el último instante por amor a Dios, que es el testimonio más genuino de todo el acontecer del Prof. Rivera en este mundo. A todos nos confiaba que cada día de más que se le ofrecía era una gracia a la que él se abrazaba para ponerse al servicio de nuestro Padre Celestial con todas sus fuerzas. Así, esperanzado, lleno de paz y de proyectos, le ha sorprendido su tránsito.

Desde aquí damos gracias a Dios por su presencia con el convencimiento de que la emoción que nos ha producido su partida queda en gran parte compensada por el gozo de haber tenido la gracia de contemplar cómo actúa la gracia divina en quienes se dejan moldear por ella y de haber convivido con él, o de haberlo tratado en alguna ocasión. En cualquier caso, el aliento y la fuerza de su vida será el ejemplo en el que habremos de reconocer la necesidad de vivir en ese amor que caracteriza a todos los hijos de Dios, por el cual se nos reconoce como discípulos suyos (Jn 13,35). Que El nos conceda la gracia de saber emular al P. Enrique en cuanto ha hecho por su honor y gloria. Así, recordando las emotivas palabras con las que finalizó la homilía de sus exequias su Provincial, el P. Manuel Muñoz, le saludamos desde estas páginas con el respeto, la admiración y el cariño que siempre le profesamos: "¡Adelante, auriga! ¡Adelante, maestro!”.

Isabel Orellana Vilches

Vista Alegre 2-10, $3^{\circ} \mathrm{B}$

37003 Salamanca 